\title{
City Branding: uma marca para a cidade de Piracicaba-SP que a represente através da visão do seu povo, da sua cultura e da sua história City Branding: a brand for the city of Piracicaba-SP that represents it through the vision of its people, its culture and its history
}

\author{
Kleiton Web Rodrigues Viana
}

marcas de cidades, identidade visual, cultura, sociedade

\begin{abstract}
A conquista de um espaço na cabeça das pessoas está levando marcas de produtos e serviços a adotarem estratégias de branding como forma de expressar seu posicionamento e se diferenciar dos concorrentes. Deste modo, nas últimas décadas, o segmento de cidades e lugares - até então pouco explorado - busca acompanhar este movimento e passa a ganhar mais notoriedade, ao ponto de gerar uma área de estudo específica denominada Place Branding, como aponta Simon Anholt em seu livro Place Branding and Public Diplomacy. O artigo em questão tem como objetivo trazer à tona as etapas de pesquisa e construção projetual de uma representação gráfica para o município de Piracicaba, localizado no interior do estado de São Paulo. O conceito explorado no projeto almejou a criação de uma marca que refletisse o que é a cidade através da visão do seu povo, da sua cultura e da sua história. Dado este desafio, percebeu-se uma carência na documentação de processos metodológicos de projeto visual voltados à criação de marcas de lugares e cidades, englobando as áreas de branding e identidade visual, assim como uma classificação mais objetiva sobre seus tipos e implementações. Neste sentido, foram elaboradas análises de casos de marcas de place branding que obtiveram sucesso no engajamento com seu público, para que se pudesse observar suas particularidades e reproduzi-las neste projeto. Tal processo será detalhado brevemente no artigo.
\end{abstract}

\section{City branding, visual identity, culture, society}

Gaining space in people's heads is leading brands of products and services to adopt branding strategies as a way to express their positioning and differentiate themselves from competitors. Thus, in recent decades, the segment of cities and places - hitherto underexplored - seeks to keep up with this movement and has gained more notoriety, to the point of generating a specific area of study called Place Branding, as pointed out by Simon Anholt in his book. Place Branding and Public Diplomacy. The aim of this article is to bring to light the research and project construction stages of a graphic representation for the city of Piracicaba, located in the interior of the state of São Paulo. The concept explored in the project aimed to create a brand that reflects what the city is through the vision of its people, its culture and its history. Given this challenge, there was a lack in the documentation of methodological processes of visual design aimed at the creation of brands of places and cities, encompassing the areas of branding and visual identity, as well as a more objective classification of their types and implementations. In this sense, case analysis of place branding brands that were successful in engaging with their audience was elaborated so that their particularities could be observed and reproduced in this project. Such a process will be detailed briefly in the article.

\section{Introdução}

Dentre as metodologias de gestão do Branding existe uma vertente que tem como foco principal a construção e divulgação de marcas para um território, seja ele um país, uma região ou um espaço público. A esta vertente é dada o nome de Place Branding, termo cunhado por Simon Anholt. Na opinião de Ciflon e Simmons (2005, p. 242), "uma estratégia de marca de um local consiste num plano para definir a mais realista, mais competitiva e mais apelativa visão estratégica para o país, região ou cidade; esta visão tem então de ser satisfeita e comunicada". Quando a estratégia de gestão de marca de lugares é focada especificamente na valorização de cidades dá-se então o nome de city branding. Para Anholt (2007) uma das principais

Anais do 9 CIDI e 9 CONGIC

Luciane Maria Fadel, Carla Spinillo, Anderson Horta, Cristina Portugal (orgs.)

Sociedade Brasileira de Design da Informação - SBDI Belo Horizonte | Brasil | 2019 ISBN $978-85-212-1728-2$
Proceedings of the 9th CIDI and 9th CONGIC

Luciane Maria Fadel, Carla Spinillo, Anderson Horta, Cristina Portugal (orgs.)

Sociedade Brasileira de Design da Informação - SBDI Belo Horizonte | Brazil | 2019

ISBN 978-85-212-1728-2 
diferenças entre Place Branding e a simples propaganda de um lugar ou país, é que na propaganda ocorre o uso deliberado de fins políticos para manipular a opinião pública. Já no Place Branding o que se busca é a constatação de que a opinião pública é um componente essencial para alcançar um fim político. Neste sentido, Marty Neumeier (2008) é categórico ao afirmar que uma marca não é aquilo que você diz que é, mas sim, o que o seu cliente/usuário diz que ela é. Portanto nota-se aqui a importância de introduzir a percepção dos habitantes como vetores ativos no processo de definição desta identidade local. Desconsiderar a coleta destas informações pode levar o projeto à uma solução gráfica que represente de forma conceitual e ideológica os interesses de um grupo político, em vez de ser uma representação visual que esteja alinhada aos significados emitidos pela própria população.

Partindo desta reflexão, foi identificado que a cidade de Piracicaba, localizada no interior do Estado de São Paulo, carrega um grande potencial de possuir uma expressão visual gráfica que propague a sua identidade local, já que de acordo com Cecílio Elias Netto (2015), a cidade tem uma cultura muito singular, calcada especialmente na história de pioneirismo desenvolvida por seus antepassados desde os primórdios de sua povoação, em conjunto com uma personalidade autointitulada de caipiracicabanidade. Dado a sua localização geográfica, fora do trânsito do desenvolvimento urbano, com o passar dos anos Piracicaba foi preservando uma cultura bairrista muito forte, o que fez efervescer uma identidade caipira que se reflete em seu sotaque, artes visuais, música, gastronomia e comportamento - tais descobertas serão detalhadas no decorrer do artigo.

Dado esta problemática, o projeto partiu para um estudo prévio em busca de diretrizes para a criação da marca do município. Para isto o processo foi divido em quatro fases, sendo três de coleta de dados e uma de análise e reflexão das informações obtidas. Por último, uma fase se aplicação das diretrizes coletadas em uma representação gráfica final.

\section{Desenvolvimento}

Os projetos de criação de marcas de cidade são realizado em sua maioria por empresas de consultoria especializada, onde o processo metodológico é dificilmente divulgado, portanto, torna-se complexa a definição de um paralelo entre o método de criação de uma marca de produto e serviço, ao qual já se conhece sua formulação, com as particularidades de uma projeto de criação de marca de cidade. Neste sentido, valida-se a importância das fases de coleta de dados, pela carência de um método consistente e específico para a criação da marca de uma cidade ou lugar.

A identidade gráfica de uma cidade como um todo é desenvolvida a partir de sua cultura e de sua história, considerando-se, ainda, seus recursos naturais, monumentos, personagens e ícones. Ao longo do tempo, a percepção e a vivência desses aspectos objetivos e intersubjetivos desenvolvem no público interno e no público que frequenta a localidade, um sentido básico que representa a cidade e se torna a manifestação de seu espírito ou a síntese de sua identidade. (Cardoso, 2013 p. 53)

Sob essa perspectiva, a cidade Paris é romance; a cidade Milão é estilo; a cidade Washington é poder; a cidade Londres é Vanguarda; a cidade Tóquio é modernidade; a cidade Barcelona é cultura, e a cidade Nova York é Energia (D2B, 2007).

\section{FASE 1 - Como criar uma marca de cidade?}

Na fase 1, foi realizada uma análise sobre 7 cases de city brands, a fim de identificar características positivas e negativas em suas composições. A seleção dos exemplos se basearam na mescla de quatro cases extraídos do Anholt-GfK City Brands IndexSM (2015) e três que não estão no ranking, mas possuem soluções visuais interessantes e são muito significativos no segmento de city branding, sendo eles Cidade de Sidney, Cidade de Melbourne, Cidade de Toronto, I Amsterdam, I O NY, Rio 400 anos e Rio 450.

A análise recorreu de um levantamento pautado nas seguintes questões: 1) Quem criou? 2) Para quê foi criada? Quais são suas características visuais (cor, forma, tipografia e 
significado)? 3) É uma marca perene? 4) Qual o grau de recepção dessa marca perante a população do local retratado? 5) Quais fatores de sucesso e engajamento de cada case?

Atualmente, as marcas gráficas como conhecemos, desempenham os papéis mais variados e complexos. Contudo, elas já serviram no decorrer dos anos para identificar produtos ou serviços e diferenciá-los dos demais. Para Pinho (2006, p. 89), as marcas de uma forma geral exercem as seguintes funções:

- Função concorrencial: as marcas que assinalam os produtos concorrem diretamente entre si;

- Função Identificadora: ao assinalar os produtos e serviços, as marcas os identificam individualmente;

- Função individualizadora: o produto marcado e identificado torna-se um bem individualizado e único perante um conjunto de bens de marcas diferentes;

- Função de descobrimento ou revelação: depois de um produto novo ser lançado no mercado, a marca é que vai revelar sua existência ao consumidor. E ao comprar o bem, o consumidor descobre o produto que a marca assinala;

- Função de diferenciação: por meio de uma marca o produto torna-se diferenciado na sua categoria;

- Função publicitária: a publicidade busca divulgar e promover a marca do produto junto ao consumidor para que, assim, ele deixe de ser uma mercadoria anônima;

- Função de diferenciação interna: os produtos de uma mesma marca, por exemplo, são marcados para diferenciação de modelos.

Neste sentido, analisando os cases selecionados, foi possível identificar que as marcas de cidade podem ser categorizadas em tipos de acordo com o seu propósito de comunicação:

- Função institucional (Cidade de Sidney, Cidade de Melbourne e Cidade de Toronto): este tipo de marca tem como objetivo representar a instituição cidade. $\mathrm{Na}$ maioria das vezes, por meio de sua prefeitura ou administração executiva, ela organiza a arquitetura das marcas de instituições e secretarias que fazem parte do órgão principal. Essas marcas muitas vezes são funcionais pois precisam ser aplicáveis nas mais diversas situações.

- Função turística (I Amsterdam e I $\bigcirc$ NY): Com o objetivo de promover o turismo local, este tipo de marca normalmente é encomendada para propor um posicionamento de marketing e comunicação que fortaleça determinada imagem para a cidade.

- Função comemorativas e promocional (Rio $\mathbf{4 0 0}$ anos e Rio450): este tipo de marca possui uma demanda mais pontual e serve como forma de identificar determinada comemoração ou celebração que ocorre na cidade. Ambos exemplos analisados estavam associados ao aniversário da cidade do Rio de Janeiro.

Além do propósito, outras formas de categorização foram feitas para identificar intersecções entre os cases analisados, são elas: estilo, cor e aceitação popular.

Figura 1: Categorização por Propósito (Composição do autor, 2017)

\section{Categorização por PROPÓSITO}

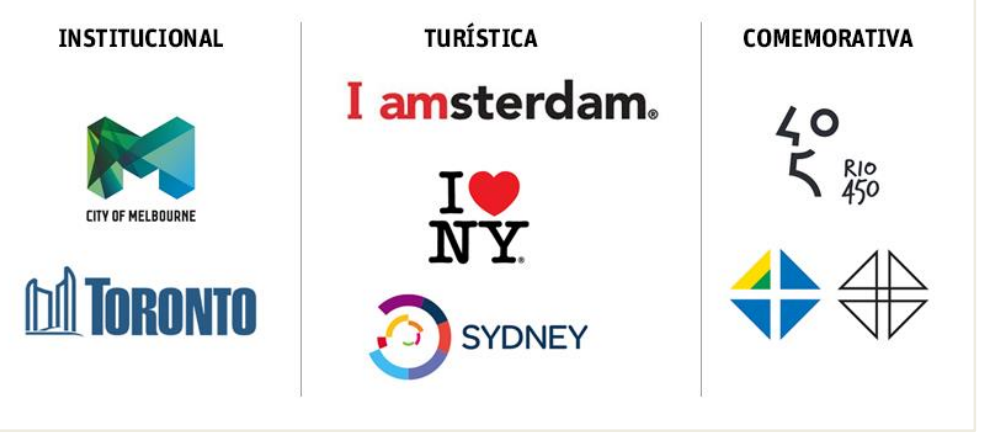


Figura 2: Categorização por Estilo (Composição do autor, 2017)

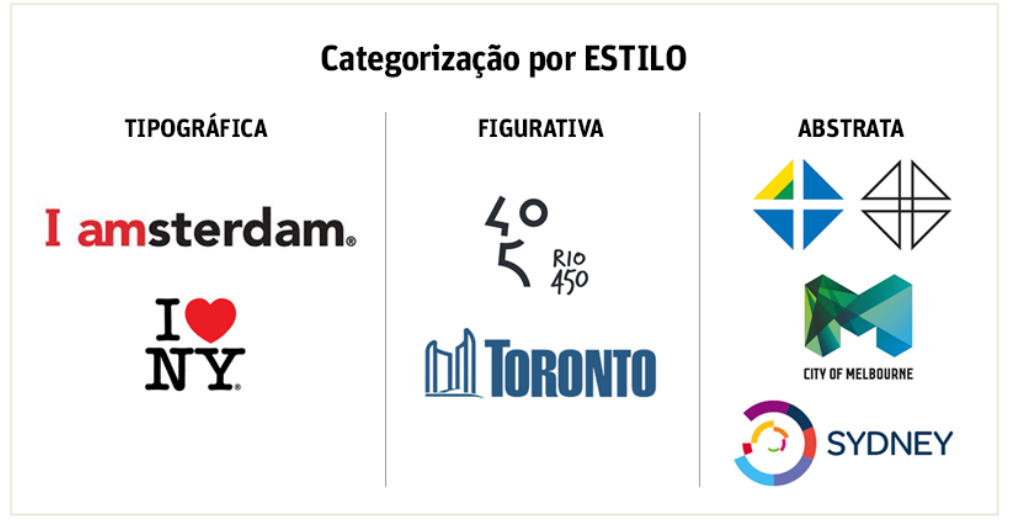

Figura 3: Categorização por Cor (Composição do autor, 2017)

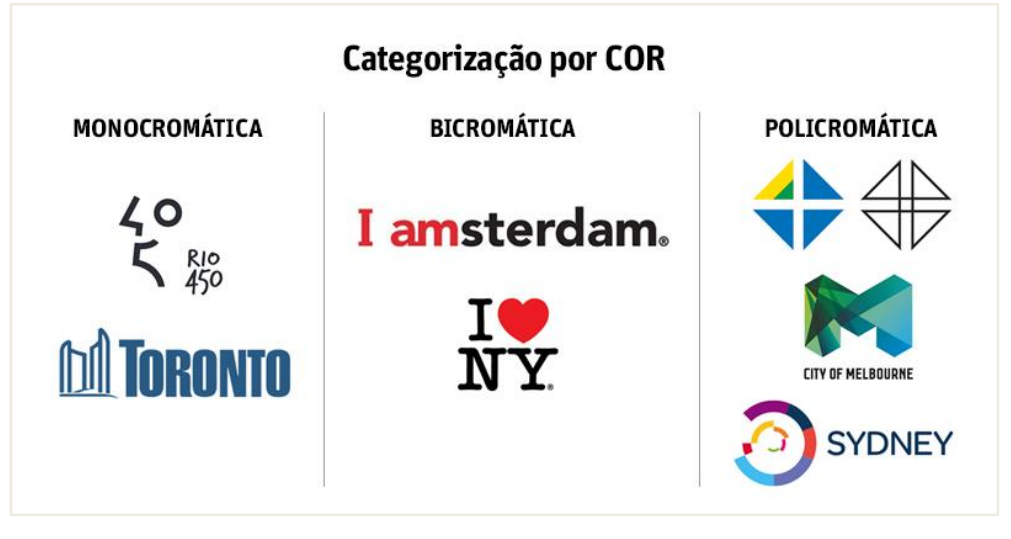

Figura 4: Categorização por Aceitação Popular (Composição do autor, 2017)

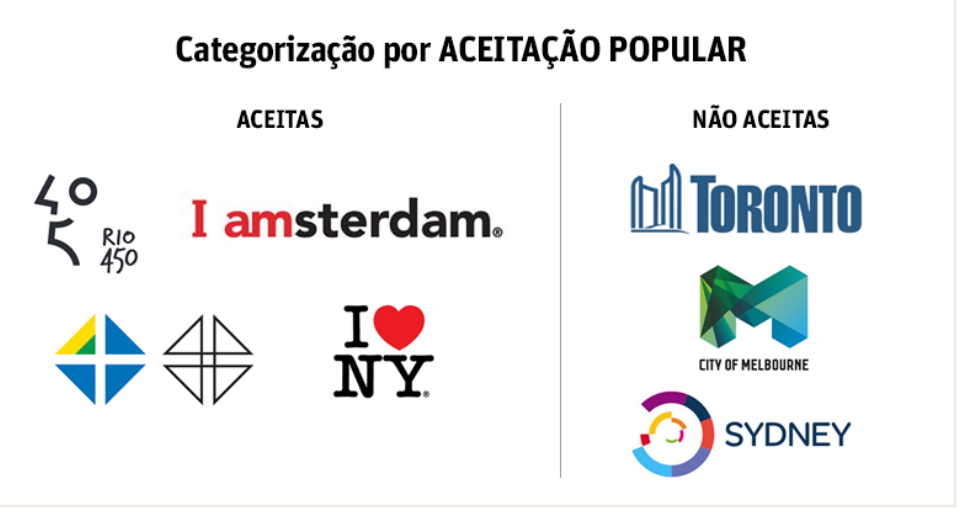

Em situações como I Amsterdam e I $\bigcirc$ NY, pode-se identificar uma iniciativa bem contemporânea de marcas que se posicionam como objeto de relacionamento som seus receptores. Esse diálogo se dá pelo campo verbal ao sugerir uma afirmação que estreia o elo semântico da marca com seu público: "Eu Sou Amsterdam" e "Eu Amo NY". No caso da Rio450 pode-se notar o mesmo esforço acontecendo, contudo, no campo visual. A representação subjetiva de um perfil humano por meio da composição modular dos caracteres 4,5 e 0 , coloca o carioca dentro da marca, servindo como plataforma para uma personalização. 
Para garantir a leitura correta dos números, a marca ganhou uma versão com a assinatura "Rio 450".

Assim como as palavras, as marcas depois de aprendidas, deixam de ser lidas e passa a ser

identificadas visualmente com seus respectivos significados. Uma vez percebida como um rosto, a

Rio450 ultrapassa seu sentido literal e projeta a sua personalidade. (Ricardo Leite - Crama Design,

2015)

Por último, o case dos 400 anos do Rio de Janeiro se prova um sucesso em solução de design e aceitação popular. Para Zoladz (2005) o sucesso e aceitação popular do símbolo se dá ao fato do abstracionismo da forma ser tão grande, que gera um distanciamento dos aspectos físicos que fazem referência direta à cidade do Rio de Janeiro. Logo, a falta dessa ligação incita a população, a ver naquele sinal propostas de fantasia, onirismos e exercícios lúdicos de experimentações plásticas. Tais estímulos geram como resultados aplicações das mais diversas, sempre mantendo a estrutura original do logo.

O povo aceitou e usou amplamente o símbolo, enriquecendo a sua estrutura inicial. A ideia foi capaz de suportar transformações e modificações sem perda de seu reconhecimento imediato: como as letras suportam qualquer grafismo; como o som se acomoda a diferentes vozes; como as palavras são ditas em diferentes sotaques; como as cores permitem diversos tons. (Magalhães)

Figura 5: Apropriações visuais da marca feitas pela população. (Composição do autor, 2017)
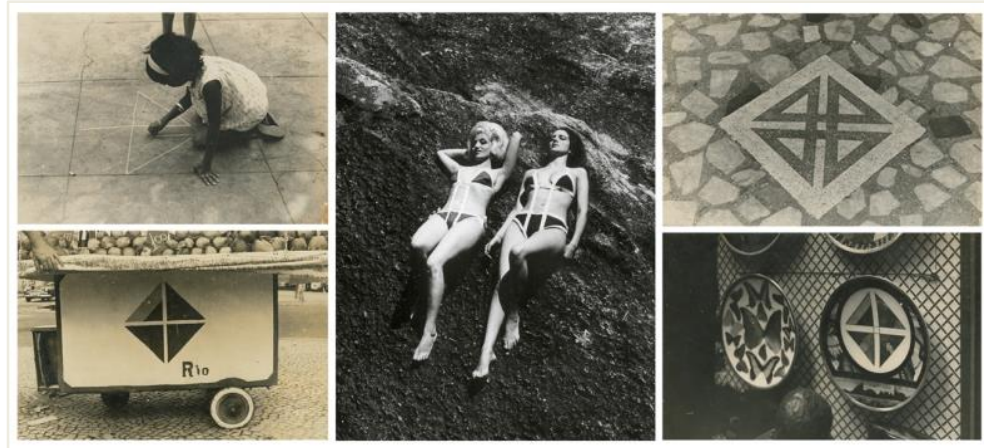

A partir da análise destes cases na categoria 'aceitação popular', é possível destacar algumas características em comum:

- Elas são em sua maioria bicromáticas;

- As soluções gráficas são objetivas e de fácil replicação;

- Possuem soluções que podem facilmente ser aplicadas no contexto urbana ou estão presentes no cotidiano das pessoas, melhorando sua pregnância e familiaridade.

- Elas propõem um diálogo com seus receptores, seja no campo verbal, colocando-os como interlocutores, ou no visual, promovendo a sua personalização e apropriação.

A proposta de uma representação gráfica que ofereça uma comunicação bilateral, tornará a sua apropriação muito mais natural e homogênea, resultando em intervenções espontâneas daqueles que se identificarem com o determinado símbolo.

\section{FASE 2: Pesquisa Iconográfica Piracicabana}

As possibilidades de expressão, percepção e comunicação desse espírito da marca cidade promovem a disseminação pública e o desenvolvimento da imagem da marca. Pois, primeiramente, essa advém da interação do público com a cidade e, em seguida, começa a ser também percebida de maneira indireta, através da repercussão decorrente da comunicação oficial ou informal da marca (Gaio \& Gouveia, 2007).

Os autores Gaio \& Gouveia (2007) apresentam os fatores que, de maneira geral, influenciam na construção da imagem da marca cidade:

- As caraterísticas e dimensão da população e do espaço;

- O seu status ou poder político;

- A sua taxa de criminalidade; 
- O número e o caráter das instituições nacionais situadas dentro da cidade;

- A sua localização;

- O seu histórico;

- O seu valor turístico e cultural;

- O modo com a cidade aparece como um produto (product placement) em filmes ou séries da televisão;

- A natureza e o volume de cobertura dos eventos da cidade pela mídia;

- A sua beleza natural e patrimonial.

Partindo deste pressuposto, criou-se questionário online iniciando no dia 4/01/2017 às $18 \mathrm{~h} \mathrm{e}$ finalizando no dia $8 / 01 / 2017$, às $16 \mathrm{~h} 30$, totalizando 224 respostas. Analisando suas respostas, percebeu-se que em vários momentos alguns itens se repetiram mesmo que em contextos diferentes. O 'Rio Piracicaba' ao lado do 'Peixe' e do 'Sotaque', são no geral, os elementos culturais e simbólicos mais presentes na cabeça dos entrevistados. A cada resposta analisada é possível perceber uma relação, mesmo que mínima, com qualquer um desses três itens.

A região da Rua do Porto é outro tópico muito lembrando durante a pesquisa, ora relacionada a gastronomia, ora a história e cultura. O peixe é desde o animal que melhor representa a cidade, quanto o ingrediente principal da culinária típica piracicabana. O sotaque caipira está presente tanto na rotina das pessoas quanto em suas músicas mais tradicionais. Composto pelo seu "r retroflexo", ele é fácil identificado em qualquer lugar. Esse elemento também compõe o "jeito caipira de ser", chegando a ser tão particular que ganha o nome de caipiracicabanidade. Netto (2015).

A música de viola é muito lembrada quando relacionada ao sotaque e as frases mais icônicas da cidade. Não à toa o hino oficial do município é composto por uma moda de caipira, que tem em seu refrão o verso mais lembrado em pesquisa, o "Piracicaba que eu adoro tanto".

No campo urbano e arquitetônico, além da Rua do Porto, outro item muito importante para o imaginário piracicabano é o Engenho Central. Um antigo engenho de açúcar localizado as margens do Rio Piracicaba que hoje ser de como um complexo cultural que abriga museus e um teatro.

Por fim, os itens identificados em pesquisa que compõem a iconografia piracicabana e que servirão de base para a criação da marca cultural gráfica de Piracicaba são:

1. Rio

2. Peixe

3. Jeito de ser

4. Rua do Porto

5. Sotaque

6. Música de Viola

7. Gastronomia

8. Engenho Central

Tendo isto em mente, é possível afirmar que são esses os elementos que melhor identificam a cidade e podem ser representados das mais variadas formas, pois muitos deles são passiveis de figuração. No caso do Sotaque, temos uma ferramenta de linguagem que abre uma gama de possibilidades e experimentações.

Durante a análise das respostas, poucos elementos foram deixados de lado e na sua maioria, foram somados com outros tópicos por serem comuns. Um exemplo para isso é quando perguntando qual frase melhor representa a cidade e as repostas giram em torno dos versos da música Rio de Lágrimas, que no decorrer da análise foi somado ao item Rio Piracicaba, por possuir uma associação direta a ele.

\section{FASE 3: Entrevista com o historiador Cecílio Elias Netto}

Cecílio Elias Netto é um respeitado jornalista e escritor piracicabano que possui o trabalho de estudar e documentar sobre a cultura caipira e a história da cidade de Piracicaba. Com mais de 
20 livros publicados, Cecílio se destaca por ser o autor do "Dicionário do Dialeto Caipiracicabano", no qual há 30 anos documenta os verbetes e expressões da linguagem caipira do interior do Estado de São Paulo. Outra obra em destaque é a trilogia de livros "Piracicaba que Amamos Tanto", "Piracicaba, Um Rio Que Passou em Nossas Vidas" e "Piracicaba, A Doçura da Terra" escrita em homenagem aos 250 anos da cidade de Piracicaba, que ocorre em agosto de 2017.

A entrevista foi realizada em 12/12/2016 das $19 \mathrm{~h} 34$ às $20 \mathrm{~h} 52$ em sua residência. Nela possível identificar alguns fatores que ajudaram a direcionar o projeto. Em determinando momento da entrevista, Netto afirma existir um procura muito grande, principalmente por jovens, em conhecer e entender melhor sobre a cultura piracicabana (ao mesmo tempo em que vê isso como um reflexo da globalização, em que as pessoas procuram algo que valide a sua identidade), trazendo à reflexão de que existe sim uma abertura por parte da população para algo que sintetize este sentimento de pertencimento ao local, seja isto em um elemento gráfico, um termo, uma frase ou qualquer outra expressão.

Para o historiador, existe uma alma que permeia a cultura da cidade ao qual ele denomeia como caipiraicabanidade, que, em síntese, é um comportamento peculiar que une o sotaque com 'jeito de ser' de quem mora em Piracicaba. Este, segundo ele, é o maior ativo cultural da cidade, seguido por seu Rio e suas belezas naturais.

\section{Fase 4: Análise dos dados e aplicação do método}

No livro The city as a brand: Orchestrating a unique experience, Florian (2002) alerta que as "cidades estão a tornarem-se impessoais, anónimas e no final inabitáveis". Como solução, o autor propõe que as cidades "precisam necessitam de alma, tal só acontece se desenvolverem uma identidade original e inimitável, oferecendo uma experiência única".

A primeira diretriz conceitual parte da defesa de que a caipiracicabanidade, apontada por Cecílio Elias Netto, é o valor cultural a ser retratado na marca. Este jeito peculiar se ser, que foi identificado até mesmo na pesquisa iconográfica, sempre estava acompanhado de impressões relacionadas ao sotaque caipira, personalidade receptiva e a simplicidade na forma de encarar as coisas. Outra característica é a fidelidade e respeito com suas raízes e tradições, a mesmo tempo que há uma abertura para conhecer e vivenciar novas possibilidades de interação cultural, e, é nesta relação de tradicional/contemporâneo e antigo/novo, que a habita a complexidade de representação gráfica deste projeto.

Desta forma, o ponto de partida foi selecionar todos os itens lembrados na pesquisa iconográfica e distribuílos em uma tabela que analisa item a item a partir de algumas características como:

- Valor: aqui é necessário saber se este item é tangível ou intangível. Essa reflexão serve para mensurar seu grau de representação simbólica.

- Como ilustrar: neste tópico descrevemos todas as coisas que fazem referência ou alusão ao item em questão, a fim de encontrar as convenções mais comuns.

- O que evoca: aqui busca-se identificar qual sensação, emoção ou ação este consegue expressar.

Tabela 1: Análise da Iconografia (Autor, 2017)

\begin{tabular}{l|l|l|l} 
Item & Valor & Como ilustrar? & O que evoca \\
\hline Rio & Tangível & $\begin{array}{l}\text { Água, movimento, ondas, salto, } \\
\text { corredeiras, }\end{array}$ & $\begin{array}{l}\text { Agitação, direção, } \\
\text { sinuosidade, movimento }\end{array}$ \\
\hline Peixe & Tangível & $\begin{array}{l}\text { Forma anatômica, guelras, } \\
\text { escamas }\end{array}$ & Cardume, coletividade \\
\hline Jeito de ser (caipira) & Intangível & $\begin{array}{l}\text { Simplicidade, amor as suas } \\
\text { raízes, sentimento de } \\
\text { comunidade, }\end{array}$ & Simplicidade \\
\hline Rua do Porto & Tangível & $\begin{array}{l}\text { Arquitetura, casas, repetição, } \\
\text { barcos }\end{array}$ & Comunidade, origem \\
\hline Sotaque & Intangível & Letras, expressões, "R" puxado & Pertencimento \\
\hline
\end{tabular}


Viana, K. | City Branding: uma marca para a cidade de Piracicaba-SP que a represente através da visão do seu povo, da sua cultura e da sua história

\begin{tabular}{l|l|l|l} 
Música & Intangível & $\begin{array}{l}\text { Versos, instrumentos musicais, } \\
\text { efeitos sonoros, áudio, viola, } \\
\text { violeiro }\end{array}$ & $\begin{array}{l}\text { Tradição, cultura, } \\
\text { nostalgia }\end{array}$ \\
\hline Gastronomia & Tangível & $\begin{array}{l}\text { Comida, prato típico, receita, } \\
\text { talheres }\end{array}$ & Sensações \\
\hline Engenho Central & Tangível & Arquitetura, tijolos, chaminé & Poder, história \\
\hline
\end{tabular}

É possível perceber que o que se entende por Piracicaba é na verdade um coletivo de coisas e valores dos mais diversos tipos. Essa diversidade de certa forma dificulta ainda mais a proposta de se escolher um único item que identifique todos os demais. Desenvolver uma marca para todos os itens também iria exigir muito mais tempo de elaboração e estudo. Logo, vale refletir qual dos itens citados na pesquisa iconográfica melhor representa a cidade de uma forma geral e com qual linha estética ele deve ser ilustrado para que ainda pertença a essa cultura.

Considerando que a caipiracicabanidade é o valor cultural que deverá ser retratado nessa marca, algumas palavras presentes na tabela foram escolhidas para servirem de atributos verbais para o projeto. São elas: Rio, peixe, jeito caipira, sinuosidade, movimento, cardume, coletividade, simplicidade, tradição e cultura. Essas palavras serão usadas na construção de um painel semântico que irá determinar o conceito visual do projeto.

Ainda buscando validar qual item melhor representa a cidade, um segundo estudo foi realizado levando em consideração o levantamento dos principais estilos e manifestações artísticas presentes na cidade. Em seguida, observou-se seu conteúdo simbólico e imagético, na tentativa de identificar elementos que ajudem na definição de um censo comum.

Tabela 2: Análise dos estilos artísticos (Autor, 2017)

\begin{tabular}{l|l} 
Estilo & Assuntos retratados \\
\hline Artesanato & Cultura local, peixe, pontos turísticos, pamonha \\
\hline Belas Artes & Paisagens piracicabanas, Rio, cotidiano, cultura caipira \\
\hline Arte Urbana & Peixe, cultura ribeirinha, garças, lara \\
\hline Arte Naïf & Cultura caipira, peixe, costumes e tradição \\
\hline Humor e Artes Gráficas & Política, esporte, cotidiano \\
\hline
\end{tabular}

Dentre as opções, o destaque vai para a Arte Naïf que costuma retratar em suas peças, assuntos voltados a cultura caipira, peixe, costumes e tradição, Tais temas estão alinhados com os atributos verbais selecionados na tabela anterior, assim como os valores que caracterizam a caipiracicabanidade. Das técnicas existentes dentro dessa vertente artística, foi escolhida a xilogravura pela sua grande representatividade no cenário piracicabano.

Figura 6: Representações de Arte Naïf encontrada na cidade (Composição do autor, 2017)

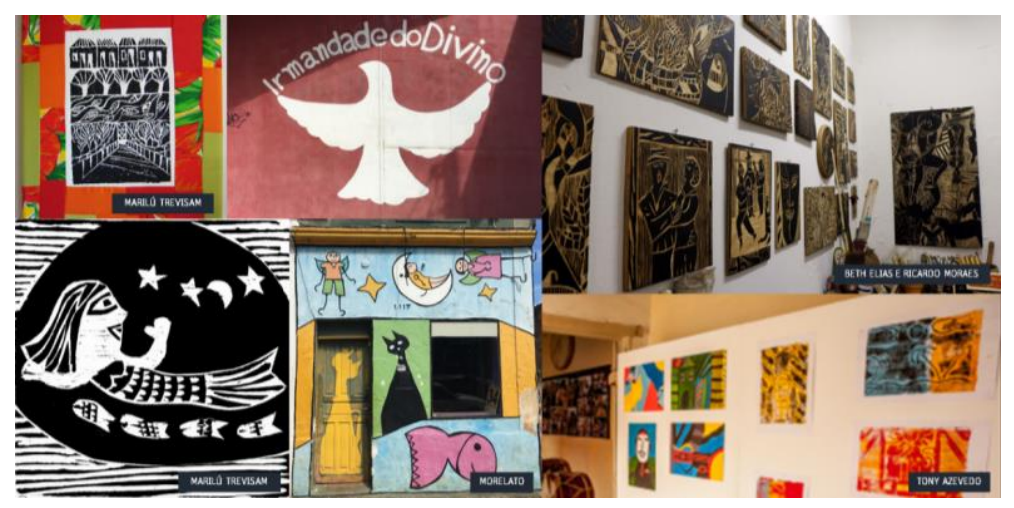

Tendo isso em mente, as diretrizes de criação a serem seguidas na concepção da marca gráfica final, foram distribuídas em quatro tópicos: 
1. Forma: A linha visual do desenho será baseada no estilo artístico que melhor represente o "jeito de ser caipira", no caso a xilogravura.

2. Conteúdo: A mensagem visual a ser passada deve fazer referência ao elemento que for identificado na análise como o que melhor consegue sintetizar a maioria dos valores presentes na iconografia piracicabana.

\section{Criação da marca gráfica}

Neste capítulo constam as experimentações gráficas que foram realizadas a partir da definição dos atributos na Fase 4, sendo eles: Rio, peixe, jeito caipira, sinuosidade, movimento, cardume, coletividade, simplicidade, tradição e cultura. Utilizando como base as características de marcas que foram aceitas pelo público, identificadas na Fase 1.

Para sintetizar os atributos em um único símbolo, optou-se pela utilização do peixe, por ilustrar um elo singular entre o rio e a cidade. Conforme Chevalier \& Gheerbrant (2009), o peixe é, bem entendido, o símbolo do elemento água, ao qual ele vive. Ele também está associado ao nascimento ou a restauração cíclica. Complementando o significado de tradição e contemporaneidade que se busca no projeto.

Em seguida, foi realizado um painel semântico para observar como este animal é ilustrado tanto de forma isolada, como em situações de padronagens. Esta análise serve para identificar convenções, além de evitar também que o material final deste projeto seja similar a outro já existente.

Figura 7: Referências de peixe (Composição do autor, 2017)

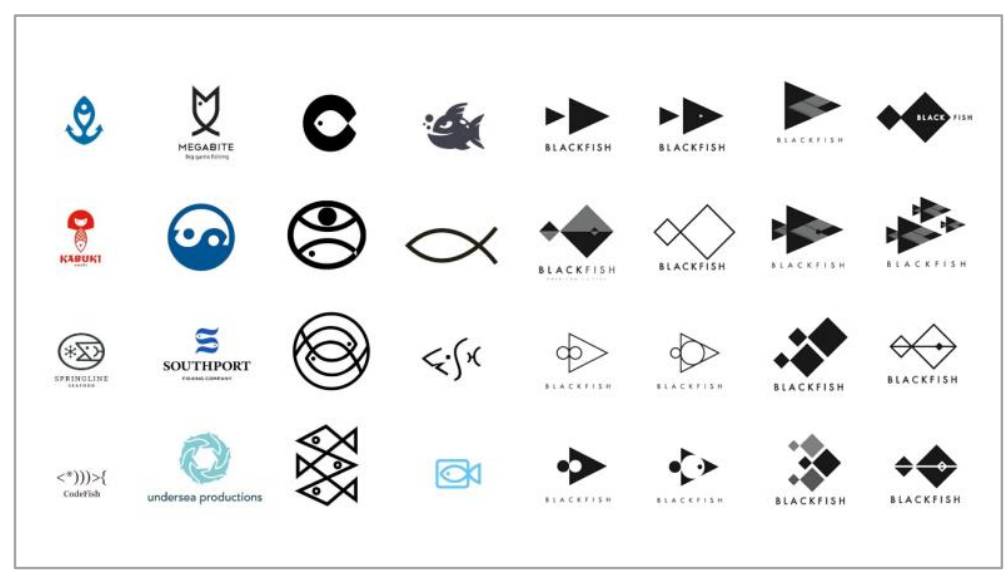

Figura 8: Referências de padronagens de peixes (Composição do autor, 2017)

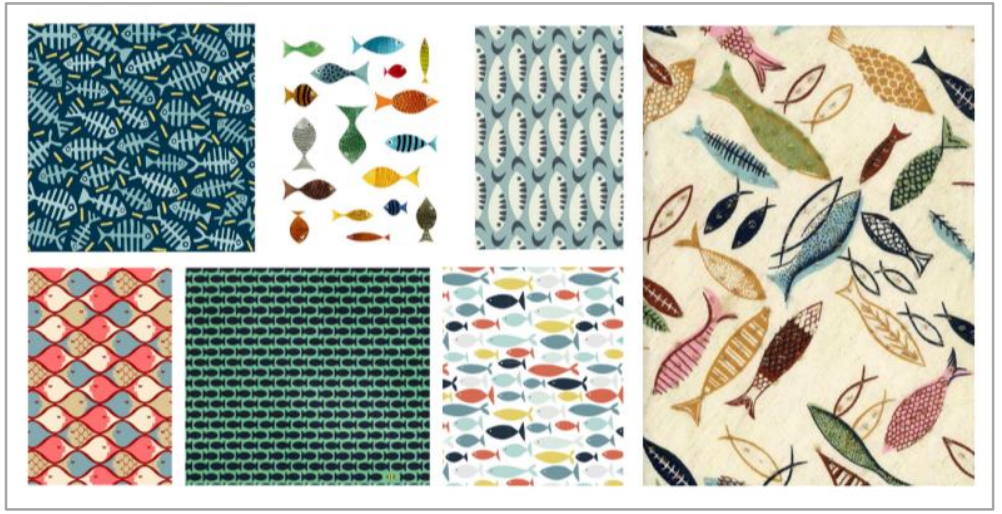


Neste momento identificou-se a dificuldade que há em ilustrar esse tipo de organismo de forma modular e geométrica. O peixe em si possui uma estrutura de complexo encaixe inverso, gerando contra formas indesejadas. A solução encontrada foi buscar ilustrá-lo em movimento diagonal, assim, assimilando-se à um símbolo de ying yang, a forma compõe um bloco que pode ser encaixado subsequentemente.

Figura 9: Rascunhos de peixe (Autor, 2017)

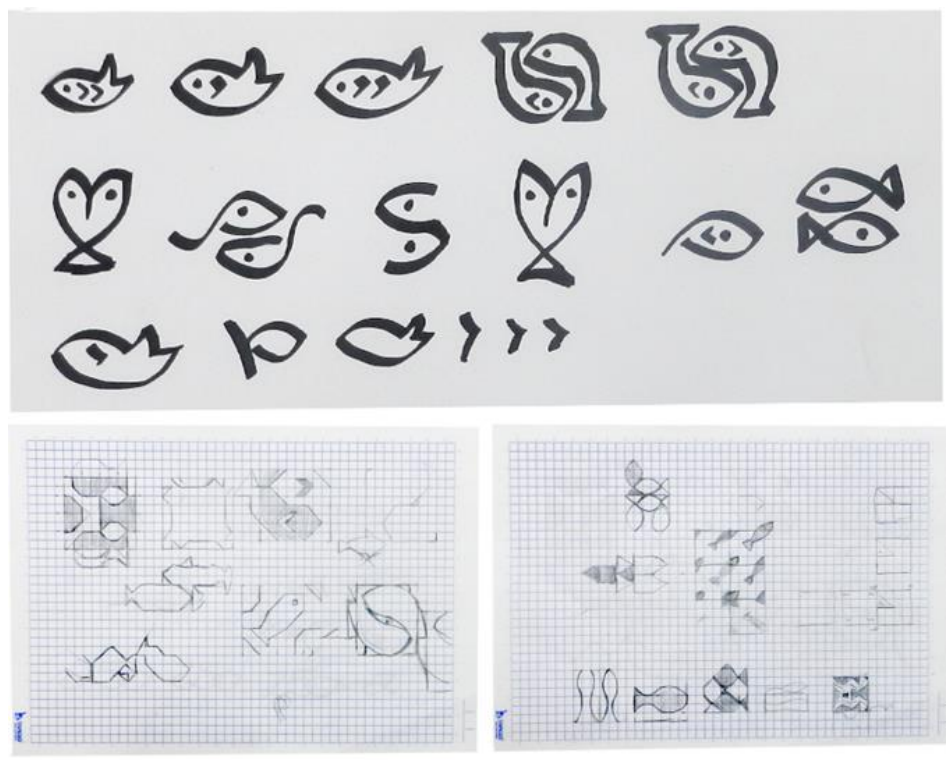

Figura 10: Rascunhos digitais de padronagem (Autor, 2017)

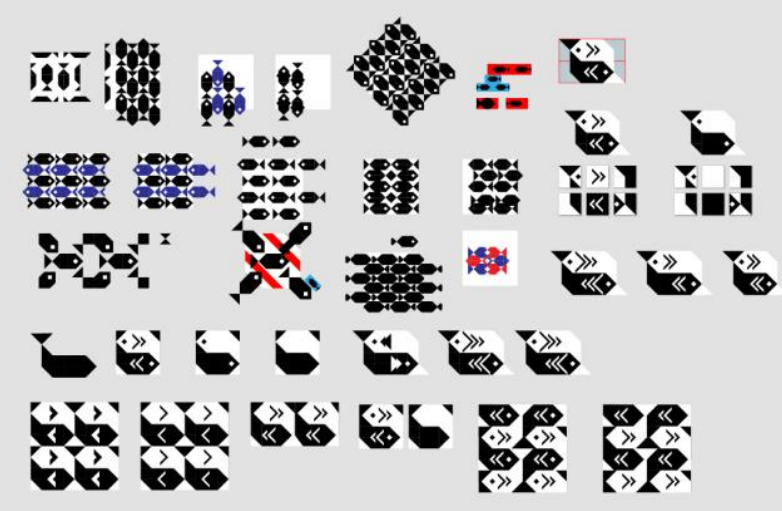

No final das experimentações, chegou-se a quatro opções de desenho que facilmente poderiam ser adaptados para uma padronagem. A primeira com os peixes um pouco maior $e$ sua cauda mais evidente. A segunda é o mesmo desenho da primeira acompanhada por uma versão da padronagem onde os peixes estão em posições opostas, reforçando a percepção de movimento. Na terceira versão o peixe é mais compacto. Junto com seu reflexo ele compõe uma forma quase circular, que também consegue ser replicada no padrão. Na quarta opção, uma variação da terceira surge como possibilidade para deixar mais evidente a forma de onda na padronagem, contudo, perde-se muito do elemento peixe, ficando a cargo de interpretação somente quando o elemento está isolado do padrão. 
Figura 11: Opções de peixes e padronagens (Autor, 2017)

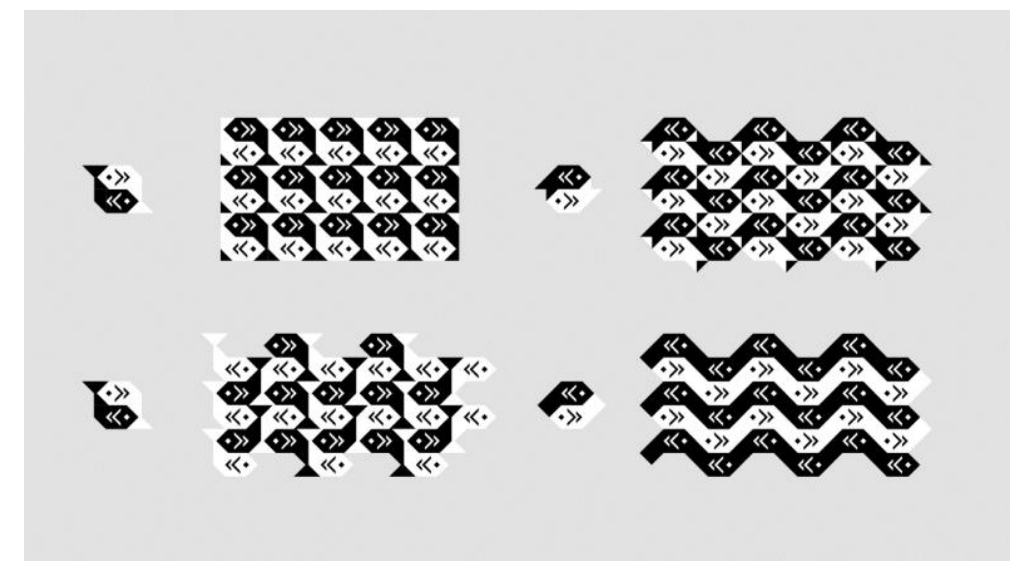

A solução escolhida foi a terceira opção, pois acredita-se no seu potencial como elemento gráfico, já que une o peixe e a percepção de onda quando ele está inserido no corpo do padrão. Com base nas referências visuais identificadas na análise dos estilos artísticos, observou-se que a xilogravura possui formas muito peculiares e rústicas. Seguindo esta linha visual, a forma ilustrada buscou remeter à uma mescla desta técnica com uma geometria mais formal e contemporânea, resultando em um símbolo cheio de personalidade e significado.

Figura 12: Opção escolhida para o símbolo (Autor, 2017)

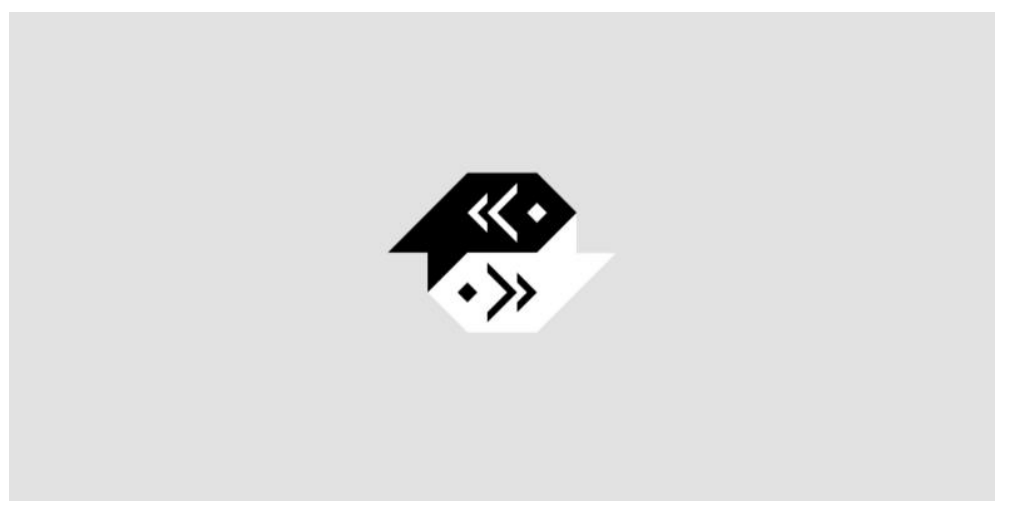

Conforme orientado nas diretrizes de criação, a possibilidade de aplicar esse elemento gráfico no cenário urbano corresponde a um dos diferencias analisados nos cases do grupo 'aceitação popular'. Logo, foi feito um estudo de como seria sua aplicação formal em um ladrilho, que servirá de base para a composição de uma calçada. 
Figura 13: Versão do símbolo para ladrilho (Autor, 2017)

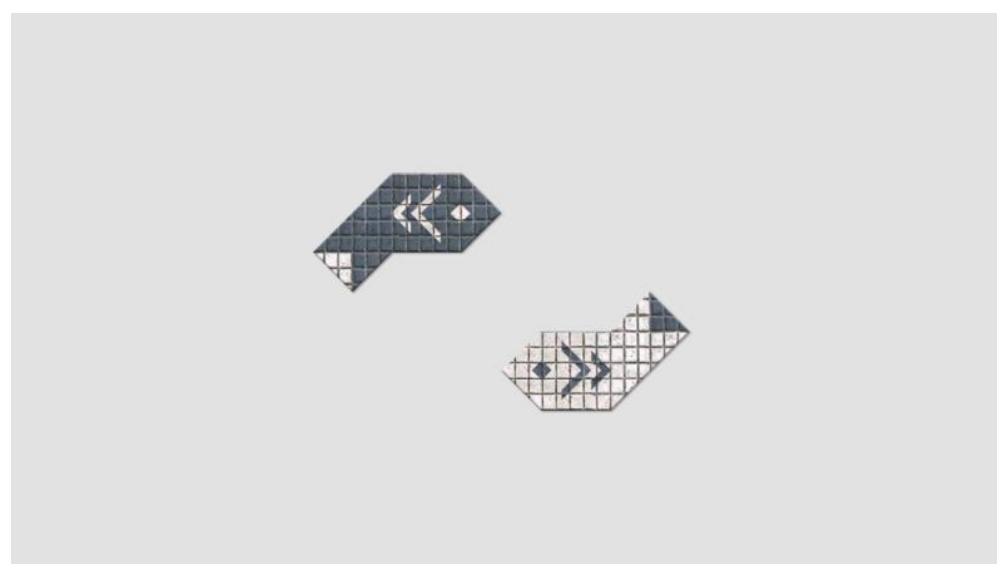

Figura 14: aplicação do ladrinho em calçada (Autor, 2017)

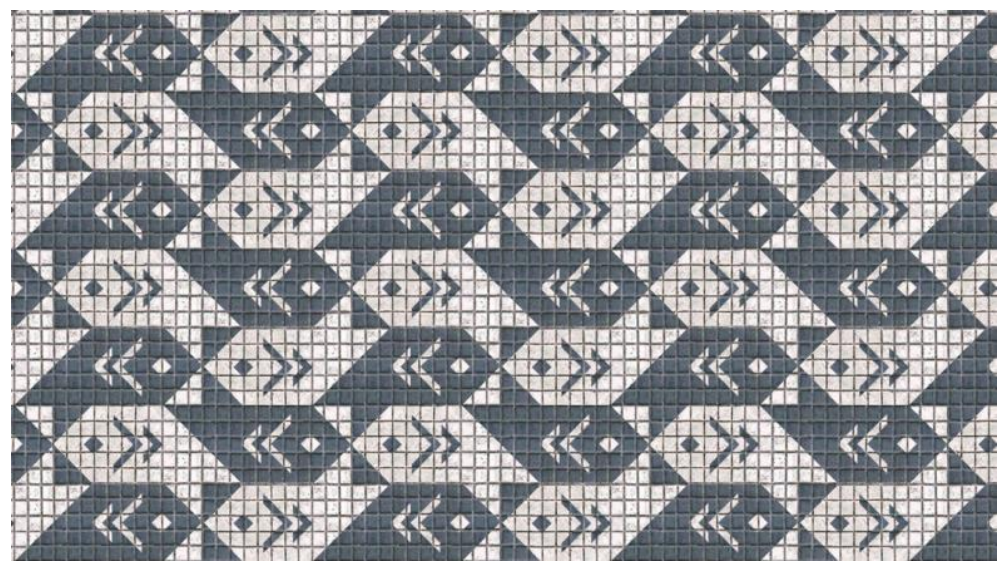

\section{Considerações finais}

O resultado do projeto foi uma marca que buscou unir as diretrizes criativas com os atributos identificados nas pesquisas, equalizando os fatores para chegar em uma proposta que expressasse de forma clara e objetiva o que a cidade representa visualmente. O público de uma cidade é grande e diverso, logo, identificar um fator em comum passível de síntese para consolidar visualmente esta percepção geral, foi o grande desafio deste projeto. Contudo, acredita-se que os resultados alcançados cumpriram seus objetivos projetuais de design e os questionamentos gerados pelas pesquisas incentivam a aprofundar o conhecimento na área de city branding e a buscar entender cada vez mais a relação entre design, política e sociedade.

\section{Referências}

Anholt, S. (2007). Competitive identity: The new brand management for nations, cities, and regions. New York: Palgrave Macmillan.

. Branding de Locais e países. In: CLIFTON, Rita \& SIMONS, John. O Mundo das marcas. Lisboa: Actual editora, 2005,

. The Anholt City Brands Index: How the world views its cities. London: GMI 2006,

Branding Nations. Brand Stategy. n. 196, 2005. 
Cardoso, H. A. T. G. (2013). Design Gráfico Na Construção Da Identidade Visual Da Marca Turística em City Branding. Tese (Mestrado). Florianópolis, Brasil: Universidade Federal de Santa Catarina

Clifton, R.; \& Simmons, J. (2005). O mundo das Marcas. Lisboa: Actual Editora, 284 p.

Chevalier, J.; \& Gheerbrant, A. (2009). Dicionário de Símbolos - 23aㅡ ed. Rio de Janeiro: 7 Letras.

Crama Design (2015). A criação da Marca dos 450 anos da cidade maravilhosa. Rio de Janeiro: Editora Senac.

D2B - Design To Branding Magazine (2007). São Paulo, v. 3.

Bülteni, B. New Anholt-GfK "City Brands" Ranking Places Three US Cities in the Top 10. Disponível em: < http://www.gfk.com/tr/icgoerueler/press-release/new-anholt-gfk-citybrands-ranking-places-three-us-cities-in-the-top-10/ > Acesso em 5 nov. 2016.

Florian, B. (2002). The city as a brand: Orchestrating a unique experience, in hauben, T., Vermeulen M. and Patteuw, V. (ed), City Branding: Image Building and Building Images, NAI Uitgevers, Rotterdam, The Netherlands.

Gaio, S., \& Gouveia, L. (2007). O Branding Territorial: uma abordagem mercadológica à Cidade. Revista A Obra Nasce. Edições UFP.

Magalhães, A. O designer / Projetos / Quarto Centenário. Disponível em < http://www.aloisiomagalhaes.org/ > Acesso em 26 nov. 2016

Magalhães, A. IV Centenário. Disponível em: < https://aloisiomagalhaesbr.wordpress.com/historia-urbana/rio/4o-centenario-do-rio/ > Acesso em 26 nov. 2016

Martins, L. B. Marcas históricas. Disponível em: < http://vejario.abril.com.br/materia/cidade/rio450-anos-logotipo > Acesso em 26 nov. 2016

Multirio. A cidade em seus 400 anos de fundação. Disponível em: < http://multirio.rio.rj.gov.br/index.php/estude/historia-do-brasil/rio-de-janeiro/71-um-riode-muitos-janeiros/3364-o-rio-de-janeiro-em-seus-400-anos-de-fundacao > Acesso em 26 nov. 2016

Netto, C. E. (2016). Dicionário do Dialeto Caipiracicabano - Arco, Tarco e Verva... 6ª Edição. Piracicaba: ICEN - Instituto Cecílio Elias Netto.

Netto, C. E. (2016). Piracicaba - Um Rio que passou em nossas vidas. 1를 Edção - Piracicaba. ICEN Instituto Cecílio Elias Netto.

Netto, C. E. Pamonhas de Piracicaba. Disponível em: < http://www.aprovincia.com.br/secos-emolhados/opiniao/pamonhas-de-piracicaba/ > Acesso em 14 de jan. 17.

Neumeier, M. (2008) The brand Gap = O Abismo da marca: Como construir a ponte entre a estratégia o design. São Paulo: Bookman.

Pinho, J. B. (1996). O Poder das marcas. São Paulo: Summus, 1996. 150 p.

Agência Pomar. Place Branding: Posicionamento de marca de cidades, estados e lugares de interesse turístico e econômico. Agência Pomar. Disponível em: < http://www.agenciapomar.com.br/place-branding/ > Acesso em 13 out. 2016 
Viana, K. | City Branding: uma marca para a cidade de Piracicaba-SP que a represente através da visão do seu povo, da sua cultura e da sua história

Zoladz, R. W. V. (2005). Imaginário Brasileiro e zonas periféricas: algumas proposições da sociologia da arte. Rio de Janeiro: 7 Letras.

\section{Sobre o(a/s) autor(a/es)}

Kleiton Viana, Pós-graduado, Unicamp, Brasil <kleitonwrviana@gmail.com> 